\title{
Discrepancy in Taiwanese psychiatrists' preferences for long-acting injectable antipsychotics across facilities: a nationwide questionnaire survey
}

This article was published in the following Dove Press journal:

Neuropsychiatric Disease and Treatment

\author{
Chun-Hao Liu',2 \\ Po-Hsin Tsai ${ }^{2,3}$ \\ Ching-Yen Chen ${ }^{2,3}$ \\ 'Department of Psychiatry, Chang \\ Gung Memorial Hospital at Linkou, \\ Taoyuan, ${ }^{2}$ College of Medicine, \\ Chang Gung University, Taoyuan, \\ ${ }^{3}$ Department of Psychiatry, Chang \\ Gung Memorial Hospital at Keelung, \\ Keelung, Taiwan
}

Background: Although many studies have discussed psychiatrists' attitudes toward long-acting injectable antipsychotics (LAIs), no previous study has focused on differences in preference based on the facilities in which the psychiatrists practiced.

Materials and methods: A pilot survey was conducted in a medical center in northern Taiwan, and a questionnaire was then distributed at the annual conference of the Taiwanese Society of Psychiatry in 2013. The questionnaire included general demographic data and preferences for the use of LAIs in different situations.

Results: A total of 142 psychiatrists were included in our study. Among them, 114 were male $(80.3 \%)$, and most practiced in general hospitals $(n=110,77.5 \%)$. We found that general hospital psychiatrists were more likely to prescribe LAIs for patients in the acute stage and with positive symptoms than were psychiatric hospital psychiatrists. General hospital psychiatrists also tended to prescribe LAIs at every time point of the disease.

Conclusion: General hospital psychiatrists were more likely to prescribe LAIs than those in psychiatric hospitals. Knowing the factors affecting psychiatrists' preferences may help us to develop a further study to explore "why" psychiatrists consider or do not consider LAIs in different facilities.

Keywords: antipsychotic agents, general hospital, injections, psychiatric hospital

\section{Introduction}

Long-acting injectable antipsychotics (LAIs) are now seen by psychiatrists as advantageous in ensuring drug adherence. Many studies have demonstrated that LAIs can reduce the relapse rate and duration of hospitalization. ${ }^{1}$ For patients with poor compliance and inadequate treatment effect, LAIs can provide a choice other than oral antipsychotics to prevent relapses, ${ }^{2-4}$ lower hospitalization rates, ${ }^{3,5}$ and provide better disease control and quality of life, with less functional decline. ${ }^{6-8}$ Another advantage of LAIs is a stable plasma-drug level compared to the oral form of antipsychotics..$^{9,10}$ On the other hand, the question of efficacy and tolerability of LAIs remains, as do concerns about the side effects of antipsychotics (eg, extrapyramidal symptoms, hyperprolactinemia, sedation, and metabolic side effects). In 2002-2003, the first second-generation LAI - risperidone microspheres - was introduced to the market, and it provided an alternative choice with fewer extrapyramidal symptoms. A study comparing first- and second-generation LAIs showed that there was no significant difference in discontinuation rates due to side effects. ${ }^{11}$ Currently, two second-generation LAIs, risperidone and paliperidone, are available in Taiwan, and they are widely used in patients with poor adherence or in the community. 
There are three major types of psychiatric facility in Taiwan: general hospitals, psychiatric hospitals, and private clinics. Generally speaking, psychiatrists in general hospitals focus more on physically related mental illness, psychiatric hospitals focus more on chronic psychosis, and private clinics focus on such neuroses as anxiety complaints and sleep problems. A previous survey in the US revealed that there were three major barriers to psychiatrists utilizing LAIs: a lack of nursing support, the psychiatrist's personal preference, and insurance coverage. ${ }^{12}$ Due to nearly full coverage by the Taiwanese National Health Insurance (NHI) system, ${ }^{13}$ most medical costs are covered by NHI, including LAIs. Unlike in psychiatric clinics, well-trained nursing staff in psychiatric hospitals and general hospitals can inject LAIs. Therefore, our study focused on psychiatrists' personal preferences across different facilities. Our hypothesis was that facility was a factor influencing psychiatrists' preferences for LAIs and their strategies in choosing LAIs in clinical practice.

\section{Materials and methods}

A questionnaire was designed by the author based on clinical observations. A total of 35 psychiatrists in a medical center in northern Taiwan participated in a pilot analysis. The questionnaire was then distributed at the annual conference of the Taiwanese Society of Psychiatry in 2013. We used convenience sampling and asked the psychiatrists attending the conference to participate in the study. We included the psychiatrists who practiced in general hospitals or psychiatric hospitals and excluded those who practiced in private clinics, because of the very low number who attended at the conference. The participants filled out the survey without oversight. The study and questionnaire were approved by the Institutional Review Board at Chang Gung Memorial Hospital. The questionnaire was voluntary and totally anonymous, and there was no identifiable personal information. We informed the participants about the goal of our study at the beginning of the questionnaire while inviting them to participate. As such, the Institutional Review Board at Chang Gung Memorial Hospital did not require written informed consent from the participants.

The questionnaire collected demographic information, including sex, years of clinical experience in psychiatry, and type of practice facility. A 10-point rating scale was used to evaluate psychiatrists' preferences when choosing LAIs in different stages, duration of illness, and target symptoms, rated from most favorable (10) to least favorable (1). All the data were analyzed by independent $t$-tests to evaluate statistical significance for the different groups (years of practice, sex, facility), using SPSS version 18.0 (SPSS, Chicago, IL, USA).

\section{Results}

We included all the psychiatrists $(n=35)$ in a medical center in northern Taiwan and the other 118 (9.7\%) of 1,212 psychiatrists who attended the annual psychiatric conference. Eleven of the latter were excluded, because they practiced in private clinics. Among the 142 psychiatrists, 114 were male (80.3\%), and the majority practiced in general hospitals $(\mathrm{n}=110$, $77.5 \%$ ) (Table 1). Half $(n=71)$ had practiced for $<10$ years. There were no significant differences in prescribing LAIs based on the sex or seniority of a psychiatrist (practice experience $<10$ years vs practice experience $\geq 10$ years) (Tables 2 and 3). Compared to psychiatric hospital psychiatrists, general hospital psychiatrists significantly preferred to prescribe LAIs for patients in an acute stage $(6.1 \pm 2.7 \mathrm{vs}$ $5 \pm 2.4, P=0.049)$ and with positive symptoms $(8.2 \pm 1.5 \mathrm{vs}$ 7.2 $\pm 1.6, P=0.002$ ) (Table 4). Psychiatrists in general hospitals also preferred to initiate LAIs at different durations of the disease compared to psychiatrists in psychiatric hospitals, especially when the duration of the disease was $<5$ years and $10-15$ years (Table 5).

\section{Discussion}

To the best of our knowledge, this is the first study to explore Taiwanese psychiatrists' preference for LAIs, and also the first study to explore the preferences of psychiatrists from different facilities. The unavailability of health care staff familiar with intramuscular administration was mentioned in another study as a barrier to the use of LAIs; ${ }^{14}$ however, in our study we excluded psychiatrists practicing in private clinics that might lack nursing support, and since all of the LAIs are covered by the Taiwanese NHI, a psychiatrist's personal preference may play an important role in the utilization of LAIs in Taiwan.

Table I Demographic data of psychiatrists who participated in our study

\begin{tabular}{llll}
\hline $\begin{array}{l}\text { Psychiatrists' } \\
\text { background }\end{array}$ & $\begin{array}{l}\text { Total sample } \\
(\mathbf{n}=\mathbf{1 4 2})\end{array}$ & $\begin{array}{l}\text { General } \\
\text { hospitals }(\mathbf{n}=\mathbf{I} \text { | 0) }\end{array}$ & $\begin{array}{l}\text { Psychiatric } \\
\text { hospitals }(\mathbf{n}=\mathbf{3 2})\end{array}$ \\
\hline $\begin{array}{l}\text { Male } \\
\text { Practice experience (years) }\end{array}$ & II4(80.3) & $86(78.2)$ & $28(87.5)$ \\
$<5$ & $37(26.1)$ & $30(27.3)$ & $7(21.9)$ \\
$6-10$ & $34(23.9)$ & $28(25.5)$ & $6(18.8)$ \\
$11-15$ & $27(19)$ & $22(20)$ & $5(15.6)$ \\
$16-20$ & $22(15.5)$ & $14(12.7)$ & $8(25)$ \\
$>20$ & $22(15.5)$ & $16(14.5)$ & $6(18.8)$ \\
\hline
\end{tabular}

Note: Data shown as $n(\%)$. 
Table 2 Patterns in prescribing LAls at different stages and for different symptoms by female and male psychiatrists

\begin{tabular}{llll}
\hline $\begin{array}{l}\text { Disease stage } \\
\text { and symptoms }\end{array}$ & $\begin{array}{l}\text { Females } \\
(\mathbf{n}=\mathbf{2 8})\end{array}$ & $\begin{array}{l}\text { Males } \\
(\mathbf{n}=\mathbf{I} \mid \mathbf{4})\end{array}$ & P-value \\
\hline Acute stage & $5.7 \pm 2.5$ & $5.9 \pm 2.7$ & 0.791 \\
Stable stage & $8 \pm 1.6$ & $8.1 \pm 1.7$ & 0.805 \\
Positive symptoms & $7.8 \pm 1.7$ & $8 \pm 1.5$ & 0.544 \\
Negative symptoms & $5 \pm 2.7$ & $5.9 \pm 2.3$ & 0.084 \\
\hline
\end{tabular}

Note: Data shown as mean \pm standard deviation.

Abbreviation: LAls, long-acting injectables antipsychotics.

Although there have been many reports about the positive effects of LAIs in schizophrenic patients, psychiatrists still hold conservative attitudes about LAIs. An European survey showed that only $40 \%$ of health care providers preferred LAIs to oral antipsychotics for the first episode of schizophrenia. ${ }^{15}$ A systematic review also demonstrated that psychiatrists held negative attitudes about LAIs for the first episode of psychosis. ${ }^{16}$ This may have been because LAIs were considered to be a coercive and stigmatizing choice of treatment, especially for those who had never experienced a relapse. ${ }^{17}$ Psychiatrists in general hospitals preferred LAIs at the acute stage and for positive symptoms more than psychiatrists in psychiatric hospitals. As the major facilities caring for schizophrenic patients, psychiatric hospitals in Taiwan also have more chronic beds than general hospitals, which focus more on consultation-liaison psychiatry. In our study, we found that general hospital psychiatrists were more likely to consider LAIs in patients at the acute stage; this may be related to a concern about poor drug compliance after discharge.

We also evaluated years of practice and sex as possible factors that might have made a difference in preference. There were no significant differences between junior psychiatrists and senior psychiatrists. This result was contrary to a previous survey published in 2006, which revealed that psychiatrists aged $>50$ years offered more LAIs than younger psychiatrists. ${ }^{18}$ From 2006 to 2013, more educational programs, lectures, and publications were provided for psychiatrists,

Table 3 Patterns in prescribing LAls at different stages and for different symptoms by junior psychiatrists (clinical experience $<10$ years) and senior psychiatrists (clinical experience $>10$ years)

\begin{tabular}{llll}
\hline $\begin{array}{l}\text { Disease stage } \\
\text { and symptoms }\end{array}$ & $\begin{array}{l}\text { Junior } \\
\text { psychiatrists } \\
(\mathbf{n}=\mathbf{7 I})\end{array}$ & $\begin{array}{l}\text { Senior } \\
\text { psychiatrists } \\
(\mathbf{n}=\mathbf{7 I})\end{array}$ & P-value \\
\hline Acute stage & $6 \pm 2.3$ & $5.7 \pm 3$ & 0.489 \\
Stable stage & $8.1 \pm 1.7$ & $8.1 \pm 1.7$ & 0.997 \\
Positive symptoms & $7.9 \pm 1.6$ & $8 \pm 1.6$ & 0.583 \\
Negative symptoms & $5.9 \pm 2.1$ & $5.6 \pm 2.7$ & 0.572 \\
\hline
\end{tabular}

Note: Data shown as mean \pm standard deviation. Abbreviation: LAls, long-acting injectables antipsychotics.
Table 4 Patterns in prescribing LAls at different stages and for different symptoms by psychiatrists in general hospitals and those in psychiatric hospitals

\begin{tabular}{llll}
\hline $\begin{array}{l}\text { Disease stage } \\
\text { and symptoms }\end{array}$ & $\begin{array}{l}\text { General } \\
\text { hospitals } \\
(\mathbf{n}=\mathbf{I} \mathbf{0})\end{array}$ & $\begin{array}{l}\text { Psychiatric } \\
\text { hospitals } \\
(\mathbf{n}=\mathbf{3 2})\end{array}$ & P-value \\
\hline Acute stage & $6.1 \pm 2.7$ & $5 \pm 2.4$ & 0.049 \\
Chronic stage & $8.2 \pm 1.7$ & $7.6 \pm 1.6$ & 0.079 \\
Positive symptoms & $8.2 \pm 1.5$ & $7.2 \pm 1.6$ & 0.002 \\
Negative symptoms & $5.8 \pm 2.5$ & $5.7 \pm 2.2$ & 0.928 \\
\hline
\end{tabular}

Note: Data shown as mean \pm standard deviation.

Abbreviation: LAls, long-acting injectables antipsychotics.

and more positive experiences with LAIs were shared among psychiatrists. A review article concluded that better education of staff can reshape their attitudes toward LAIs. ${ }^{19}$ More educational programs and more knowledge about LAIs can increase junior psychiatrists' preference to use them.

In our study, we failed to find a statistical difference between male and female psychiatrists in their preference for LAIs. This result differed from a previous cross-sectional study of psychiatrists in the US, which showed that nonwhite and female psychiatrists were more likely to prescribe LAIs. ${ }^{20}$ A previous telephone survey in the US showed that female physicians had more of a participatory decision-making style. ${ }^{21}$ Another survey in England showed that a more favorable patient-centered attitude was related to higher use of LAIs. ${ }^{22}$ Cultural background may explain this contradictory finding. A previous survey of psychiatric nurses in Hong Kong showed that patients were not involved in the decisionmaking process and preferred oral antipsychotics over LAIs. ${ }^{23}$ Force from mental-health providers was sometimes required to administer LAIs. ${ }^{23}$ Unlike in Western countries, a dominant male doctor figure in traditional Taiwanese society may persuade patients to receive an invasive and painful treatment, such as an LAI.

More psychiatrists considered LAIs during the chronic stage of schizophrenia than during the acute stage, and there

Table 5 Patterns in prescribing LAls for different durations of disease by psychiatrists in general hospitals and those in psychiatric hospitals

\begin{tabular}{llll}
\hline $\begin{array}{l}\text { Total disease } \\
\text { duration } \\
\text { (years) }\end{array}$ & $\begin{array}{l}\text { General } \\
\text { hospitals } \\
(\mathbf{n}=11 \mathbf{0})\end{array}$ & $\begin{array}{l}\text { Psychiatric } \\
\text { hospitals } \\
(\mathbf{n}=\mathbf{3 2})\end{array}$ & P-value \\
\hline$<5$ & $7.1 \pm 2.5$ & $5.5 \pm 2.7$ & 0.002 \\
$5-10$ & $7.3 \pm 2.3$ & $6.4 \pm 2.1$ & 0.055 \\
$11-15$ & $7.1 \pm 2.1$ & $6.1 \pm 2.4$ & 0.019 \\
$16-20$ & $6.8 \pm 2.5$ & $5.9 \pm 3.0$ & 0.077 \\
\hline
\end{tabular}

Note: Data shown as mean \pm standard deviation.

Abbreviation: LAls, long-acting injectables antipsychotics. 
was no significant difference between general hospital and psychiatric hospital psychiatrists. This result may show that LAIs have a well-recognized advantage for the long-term control of schizophrenia, rather than as an acute treatment. As a European survey concluded, most health care providers preferred LAIs to oral antipsychotics for chronic patients who had had more than two psychotic episodes. ${ }^{15}$

There were some limitations to our study. First, there was a relatively low response rate $(9.7 \%)$ from our study population; however, our response rate was slightly higher than that in a previous report of an online survey among psychiatrists, in which only $7.6 \%$ responded to the first email. ${ }^{24}$ Second, due to our convenience-sampling method, not all of the 1,212 psychiatrists who attended the annual conference received an invitation to participate in our study, and this may have led to sampling bias. Psychiatrists who completed the questionnaire may have had different preferences about LAIs than the whole population. Moreover, we cannot confirm that any one psychiatrist completed more than one questionnaire, because it was anonymous. In our study, LAIs included both first- and second-generation antipsychotics, but we did not differentiate between them in terms of psychiatrists' experiences and attitudes. We did not collect extensive information about psychiatrists' subspecialties, the scale of their facilities, or the payment system in different facilities. All of these may have contributed to the differences. Further investigation is needed to explore the factors that can result in different attitudes between general hospital and psychiatric hospital psychiatrists.

\section{Conclusion}

General hospital psychiatrists preferred to prescribe LAIs compared to those in psychiatric hospitals. This is the first study to try to understand the subjective preference for LAIs across different facilities. This was a preliminary survey. Knowing the factors affecting psychiatrists' preferences may help us to develop a further study to explore "why" psychiatrists consider or do not consider LAIs in different facilities.

\section{Author contributions}

All authors made substantial contributions to conception and design, acquisition of data, or analysis and interpretation of data; took part in drafting the article or revising it critically for important intellectual content; gave final approval of the version to be published; and agree to be accountable for all aspects of the work.

\section{Disclosure}

The authors report no conflicts of interest in this work.

\section{References}

1. Davis JM, Metalon L, Watanabe MD, Blake L. Depot antipsychotic drugs: place in therapy. Drugs. 1994;47(5):741-773.

2. Zhornitsky S, Stip E. Oral versus long-acting injectable antipsychotics in the treatment of schizophrenia and special populations at risk for treatment nonadherence: a systematic review. Schizophr Res Treatment. 2012;2012:407171.

3. Olivares JM, Rodriguez-Martinez A, Buron JA, Alonso-Escolano D, Rodriguez-Morales A. Cost-effectiveness analysis of switching antipsychotic medication to long-acting injectable risperidone in patients with schizophrenia: a 12- and 24-month follow-up from the e-STAR database in Spain. Appl Health Econ Health Policy. 2008;6(1): $41-53$.

4. Offord S, Wong B, Mirski D, Baker RA, Lin J. Healthcare resource usage of schizophrenia patients initiating long-acting injectable antipsychotics vs oral. J Med Econ. 2013;16(2):231-239.

5. Tiihonen J, Haukka J, Taylor M, Haddad PM, Patel MX, Korhonen P. A nationwide cohort study of oral and depot antipsychotics after first hospitalization for schizophrenia. Am J Psychiatry. 2011;168(6): 603-609.

6. Lloyd K, Latif MA, Simpson S, Shrestha KL. Switching stable patients with schizophrenia from depot and oral antipsychotics to long-acting injectable risperidone: efficacy, quality of life and functional outcome. Hum Psychopharmacol. 2010;25(3):243-252.

7. Marinis TD, Saleem PT, Glue P, et al. Switching to long-acting injectable risperidone is beneficial with regard to clinical outcomes, regardless of previous conventional medication in patients with schizophrenia. Pharmacopsychiatry. 2007;40(6):257-263.

8. Macfadden W, DeSouza C, Crivera C, et al. Assessment of effectiveness measures in patients with schizophrenia initiated on risperidone long-acting therapy: the SOURCE study results. BMC Psychiatry. 2011;11:167.

9. Spanarello S, La Ferla T. The pharmacokinetics of long-acting antipsychotic medications. Curr Clin Pharmacol. 2014;9(3):310-317.

10. Medori R, Mannaert E, Gründer G. Plasma antipsychotic concentration and receptor occupancy, with special focus on risperidone long-acting injectable. Eur Neuropsychopharmacol. 2006;16(4):233-240.

11. Cordiner M, Shajahan P, McAvoy S, Bashir M, Taylor M. Effectiveness of long-acting antipsychotics in clinical practice - 1: a retrospective, 18-month follow up and comparison between paliperidone palmitate, risperidone long-acting injection and zuclopenthixol decanoate. Ther Adv Psychopharmacol. 2016;6(1):22-32.

12. Getzen H, Beasley M, D'Mello DA. Barriers to utilizing long-acting injectable antipsychotic medications. Ann Clin Psychiatry. 2013; 25(4):E1-E6.

13. Cheng TM. Taiwan's new national health insurance program: genesis and experience so far. Health Aff (Millwood). 2003;22(3):61-76.

14. Velligan DI, Medellin E, Draper M, et al. Barriers to, and strategies for, starting a long acting injection clinic in a community mental health center. Community Ment Health J. 2011;47(6):654-659.

15. Geerts P, Martinez G, Schreiner A. Attitudes towards the administration of long-acting antipsychotics: a survey of physicians and nurses. $B M C$ Psychiatry. 2013;13:58.

16. Kirschner M, Theodoridou A, Fusar-Poli P, Kaiser S, Jäger M. Patients' and clinicians' attitude towards long-acting depot antipsychotics in subjects with a first episode of psychosis. Ther Adv Psychopharmacol. 2013;3(2):89-99.

17. Patel MX, Haddad PM, Chaudhry IB, McLoughlin S, Husain N, David AS. Psychiatrists' use, knowledge and attitudes to first- and second-generation antipsychotic long-acting injections: comparisons over 5 years. J Psychopharmacol. 2010;24(10):1473-1482. 
18. Heres S, Hamann J, Kissling W, Leucht S. Attitudes of psychiatrists toward antipsychotic depot medication. J Clin Psychiatry. 2006;67(12): 1948-1953.

19. Waddell L, Taylor M. Attitudes of patients and mental health staff to antipsychotic long-acting injections: systematic review. Br J Psychiatry Suppl. 2009;52:S43-S50.

20. West JC, Marcus SC, Wilk J, Countis LM, Regier DA, Olfson M. Use of depot antipsychotic medications for medication nonadherence in schizophrenia. Schizophr Bull. 2008;34(5):995-1001.

21. Cooper-Patrick L, Gallo JJ, Gonzales JJ, et al. Race, gender, and partnership in the patient-physician relationship. JAMA. 1999;282(6): 583-589.
22. Patel MX, Nikolaou V, David AS. Psychiatrists' attitudes to maintenance medication for patients with schizophrenia. Psychol Med. 2003;33(1): 83-89.

23. Patel MX, Yeung FK, Haddad PM, David AS. Psychiatric nurses' attitudes to antipsychotic depots in Hong Kong and comparison with London. J Psychiatr Ment Health Nurs. 2008;15(9):758-766.

24. Cunningham CT, Quan H, Hemmelgarn B, et al. Exploring physician specialist response rates to web-based surveys. BMC Med Res Methodol. $2015 ; 15: 32$.

\section{Publish your work in this journal}

Neuropsychiatric Disease and Treatment is an international, peerreviewed journal of clinical therapeutics and pharmacology focusing on concise rapid reporting of clinical or pre-clinical studies on a range of neuropsychiatric and neurological disorders. This journal is indexed on PubMed Central, the 'PsycINFO' database and CAS, and is the official journal of The International Neuropsychiatric Association (INA). The manuscript management system is completely online and includes a very quick and fair peer-review system, which is all easy to use. Visit http://www.dovepress.com/testimonials.php to read real quotes from published authors.

Submit your manuscript here: http://www.dovepress.com/neuropsychiatric-disease-and-treatment-journal 